\title{
VIRTUAL COMMISSIONING OF MANUFACTURING SYSTEMS A REVIEW AND NEW APPROACHES FOR SIMPLIFICATION
}

\author{
Peter Hoffmann \\ Reimar Schumann \\ Fakultät II - Abt. Maschinenbau \\ University of Appl. Sc. and Arts Hannover \\ Ricklinger Stadtweg 120 \\ 30459 Hannover, Germany \\ E-mail: peter.hoffmann@fh-hannover.de
}

\author{
Talal M.A. Maksoud \\ Giuliano C. Premier \\ Faculty of Advanced Technology \\ University of Glamorgan \\ 8 Forest Grove \\ Pontypridd, Wales, UK, CF37 1DL \\ E-mail: tmaksoud@glam.ac.uk
}

\author{
KEYWORDS \\ Modelling, virtual commissioning, manufacturing \\ systems.
}

\begin{abstract}
Virtual commissioning (VC) of manufacturing systems has been researched for more than 10 years. Its intention is to test manufacturing systems and associated control programs through simulation conducted before the real systems are realised. The expected benefits in reducing debugging and correction efforts expended during real commissioning, however, can only be achieved if sufficiently detailed manufacturing system models are available for simulation. To date, the design of such models has certainly required a high level of expertise and considerable effort, which makes virtual commissioning unattractive, especially for small and medium-sized enterprises (SME). After reviewing the current status of $\mathrm{VC}$, this paper describes some new concepts for the systematic and simplified design of manufacturing system models for VC based on model libraries and standardized recipes for the design of component models from CAD data. This work is carried out as part of the research cooperation between the University of Glamorgan and the University of Applied Sciences and Arts Hannover.
\end{abstract}

\section{INTRODUCTION}

Today the design of manufacturing systems takes place in an industrial environment characterized by significant cost constraints, shortening of product life-cycles and strategies for rapid time-to-market. For these reasons, the timeframe for manufacturing system engineering is progressively tightening whereas the demands on planning accuracy and planning quality are growing.

Manufacturing systems consist of different elements such as storage, magazines, conveyors, handling and transportation systems, machining and assembling tools, robots, control and HMI systems, often in a combination of a large number of standard parts and some purposebuilt parts or sub-systems. The development of a manufacturing system, in general, comprises several phases: facility design, mechanical engineering, electrical engineering and automation engineering (programming of robots, PLCs and HMI), which are often sequentially executed.

There are many different powerful and specialized tools for design and engineering, often with integrated simulation, however, there are great problems regarding data exchange between the different engineering phases and the different associated tools. A typical problem is the repeated data entry generating random errors. One principal problem is the missing generally accepted data exchange format which might be solved by AutomationML ${ }^{\circledR}$ (Drath et al. 2008a).

Up to now, after completion of engineering, procurement and assembly, the real commissioning is finally done. Conventionally an integrated test of the planned manufacturing system cannot be done before it has been built; consequently a considerable number of design problems and faults often remains undetected before the first system start-up. This leads in general to time and money consuming corrective measures being required during commissioning and the early production phases resulting in time delays and increased costs to all parties involved.

According to (Zäh and Wünsch 2005), referencing a study of the VDW (German Association of machine tool builders), the commissioning time consumes up to $25 \%$ of the time available for plant engineering and construction; and up to $15 \%$ is expended on correcting errors in the control software alone. As a possible solution to these problems the authors propose virtual commissioning (VC).

During VC, a simulation model of the manufacturing system is used to allow commissioning through simulation, before building the system. The goal is the early detection and correction of errors generated during planning, design and programming. VC may be conducted during all engineering phases, but at the latest after engineering has been completed.

An experimental study in virtual commissioning (Zäh et al. 2006) shows the positive effects of $\mathrm{VC}$ on the error 
rate during real commissioning. The study was conducted with two groups of control programmers. Each group had 30 individuals. One group applied VC to the software development for a machine. The results were compared to those from the second group of programmers that did not use VC. A tin can moulding press was used as a test bed, with a Siemens S7-300 PLC which uses 10 actuator outputs and 17 sensor inputs. One group programmed the PLC and tested the program afterwards in a real world commissioning on a real machine. The other group programmed by using a virtual machine model. They did not execute the real commissioning before achieving successful VC. The results showed a reduction of real commissioning time by $75 \%$, resulting from enhanced software quality at the start of real commissioning. This emphasizes the advantages of running a $\mathrm{VC}$, but the virtual machine model had already been developed in the run-up to this study, and this effort was not taken into consideration. In their conclusion the authors point out the need for simplified and accelerated model building.

\section{APPROACHES TO REALISING VC}

Investigating the feasibility of $\mathrm{VC}$ has been an academic and industrial research objective for several years. For separate verification of geometry, kinematics and mechanical design, a 3D simulation of the expected and specified mechanical behaviour is sufficient. A VC based on such simulations is able to detect mechanical resp. geometrical planning errors. For separate verification of the control programs, a simulation reflecting the specified behaviour of the manufacturing system mechanics at $\mathrm{I} / \mathrm{O}$ level is needed. A VC based on such simulations is able to detect deviations from the specified control functions. If the impact of control programs on the $3 \mathrm{D}$ mechanical behaviour of the manufacturing system is to be tested in detail in an integrated manner, modelling and simulation of the complete functional chains from control programs through sensors, actuators and drives onto the mechanical movements, is necessary which includes both, simulation of mechanical behaviour and of control programs .

An early approach to VC was presented by Auinger et al. (1999) and termed as "soft-commissioning". The authors propose $\mathrm{VC}$ because of the time consuming and expensive testing and debugging required by PLC based control software. As a test bed for their VC approach, the authors used a PLC controlled pallet transfer system. The modelling of the transfer system, based on the simulation tool ARENA ${ }^{\circledR}$, was done for the design and optimization of the manufacturing process. This model contained all of the control logic. Later they reduced the model, and the model used for the soft-commissioning no longer contained the control logic. The model provided only realistic I/O signals for the coupled PLC and visual feedback. In their experiments, they found malfunctions of stoppers caused by overlooked inverse logic and problems in the material flow. Normally such errors would only be detected during real commissioning. The modelling effort was not (probably with good cause) discussed.

In accordance with Auinger et al. (1999) the verification of control can be arranged in four basic system configurations:

1. Real plant and real control system: The traditional way of testing during real commissioning.

2. Simulated plant and real control system: "Softcommissioning" often called "hardware in the loop" (HIL). The hardware controller is necessary in advance, but a VC before building the plant is possible.

3. Real plant and simulated control system: termed "Reality in the loop" by the authors.

4. Simulated plant and simulated control system: This offers a complete VC.

$\mathrm{A} \mathrm{VC}$ in the second or fourth configuration requires the coupling between real or simulated controller and the mechanical plant simulator which can be realized with e.g. OPC. In the fourth configuration the simulation of controller and plant can run in one tool. This is for example possible for several robot controller and Siemens S7 PLC inside the plant simulation tool $\operatorname{CIROS}^{\circledR}$ (RIF 2010).

Currently, two research domains are linked to VC. The first domain deals with test and verification of control programs. This is possible by applying many different techniques, from testing on the real plant, to formal logic analysis. A comprehensive survey of 18 different methods can be found in (Danielsson et al. 2003). In addition to the 4 basic configurations mentioned above, the authors refer to hardware test panels for process simulation, which allow only a rough plant simulation, or simulation with process models blocks inside the control software tool. A useful survey of the research area related to formalization of existing PLC code was given by (Bani Younis and Frey 2003). For VC the verification of formalized control code against an abstract model of the plant, in the language of the analytical tool, would be necessary. The generation of such models is a theoretical and practical problem and a usable industrial implementation for $\mathrm{VC}$ is not foreseeable today.

In (Thapa et al. 2006) an approach for offline verification and validation of the control logic is defined and justified by the lack of tools to provide completely integrated solutions for the verification and validation of control logics. The authors propose a III-phase method and classify these phases as: Manual testing, Model checking and VC. Manual testing means checking the code on a softPLC (or simulated PLC like S7-PLCSIM) by user inputs; this is only useful for small programs or parts of programs. Model checking uses formalization as described by (Bani Younis and Frey 2003). The 
standard IEC 61131-3 code is converted to an intermediate language, transformed to timed automata and the model checked. For the virtual commissioning they coupled a virtual plant model and a softPLC running the checked standard code. The III-phase method requires considerable effort and expertise to build the virtual system, which is costly. The authors referred to the market situation where customers want to validate the process using $\mathrm{VC}$ or simulation using 3-D models and not textual verification only.

The second domain addresses the scope of the "Digital Factory" (Kühn 2006, Schlögl 2007). By means of digital models, computer-aided planning and design, computer-aided engineering, associated software tools and with the aid of integrated data management, the "Digital Factory" would permit integrated planning, simulation and validation of manufacturing processes and systems (VDI 2008). The use of the "Digital Factory" should extend to all phases of manufacturing system development. Nowadays simulation is already used intensively in some phases, e.g. material flow simulation for facility design, 3D simulation of kinematics for mechanical engineering and possibly interaction with product data at Digital Mock-Up (DMU). Off-line programming and 3D robot simulation have been used for many years, sometimes 3D human models are used today to evaluate ergonomics in design. Up to now the focus of simulation has been primarily in design and mechanical engineering, where fit and specified behaviour of mechanical plant components must be ensured.

In the context of the "Digital Factory" it is in principle possible to use the complex off the shelf engineering tools from major vendors for a $\mathrm{VC}$, but this usually requires a high level of training or in-house secondment of specialists from the vendor so that only large enterprises (e.g. in the automotive industry) selectively choose to conduct a VC. These "Digital Factory" solutions cannot solve the problems of small and medium-sized enterprises, because they normally do not have the resources to use these techniques (Westkämper et al. 2003), and there is therefore limited use of the "Digital Factory" today (Drath et al. 2008b). The generation of simulation models with consideration of mechanical and electrical planning data and control programs is especially associated with high effort.

In (Wischnewski 2007) the author described the VC procedure when using the simulation tool COSIMIR ${ }^{\circledR}$ and its extension module Cosimir Transport (Wischnewski and Freund 2004) for carrier based transport systems. The author justifies the $\mathrm{VC}$ by the exceedingly error-prone control design of transport systems originating from the use of many sensors and actuators and the complex program sequences required for the routing strategies implemented. Rossmann et al. (2007) described a VC with COSIMIR $^{\circledR}$ using an example of the iCIM manufacturing systems from
Festo $^{\circledR}$. The authors specified a reduction of engineering effort by up to $50 \%$ and an up to $50 \%$ faster start of production (SOP) when all component models were available in the internal simulation model library of COSIMIR $^{\circledR}$. Additionally, a library of reusable controller programs was developed. The effort for the first system is specified to have been $30 \%$ greater, with a 20\% delayed SOP. This emphasizes the importance of model libraries with standardised automation components.

This short review already shows the current options and limitations of VC for manufacturing systems. On the one hand beneficial effects such as reduced real commissioning time or improved planning quality are emphasized (Auinger et al. 1999, Zäh et al. 2006, Reinhart and Wünsch 2007, Wischnewski 2007, Rossmann et al. 2007) but on the other hand the modelling required for the virtual manufacturing system (if not just neglected) is judged by many authors to be difficult and associated with large effort (Moore et al. 2003, Park et al. 2006, Zäh et al. 2006), regardless of which simulation tool is used. The review shows moreover, a lack of accessible and 'easy to use' engineering and simulation environments which could assist the engineer to set up and conduct VC.

Thus this review indicates especially the need for improved model building methods to minimize the effort and expertise required to build a virtual manufacturing system, which can be used for checking control code and planned physical setup in a VC. This must comprise especially the set up and utilization of model libraries with standardised mechanical, electrical and control components in an engineering and simulation environment which is accessible even by SMEs.

\section{GENERATION OF PLANT MODELS FOR VC}

The investigation of possibilities for simplifying the generation and use of simulation models in a VC is a collaborative research project of the University of Applied Sciences and Arts (UASA) Hannover and the University of Glamorgan. The starting point for this project is the industrial $3 \mathrm{D}$ plant simulation tool CIROS $^{\circledR}$, originally developed at the institute for robot research (University of Dortmund), as a robot simulation tool COSIMIR ${ }^{\circledR}$ (Freund et al. 1994, Freund and Rossmann 1995). CIROS $^{\circledR}$ allows the integrated execution of $3 \mathrm{D}$ mechanics with robot and control programs using either internally emulated controllers or external real or virtual controllers via OPC. Besides this, CIROS $^{\circledR}$ provides features such as sensor and actuator simulation, collision detection, transport simulation for carrier based systems or AGVs, and also an XML model interface. The basic model generation concept for mechanical components within $\operatorname{CIROS}^{\circledR}$ is organized in two levels, here called high-level modelling and lowlevel modelling. 


\section{High-level Modelling}

CIROS $^{\circledR}$ allows the composition and simulation of virtual manufacturing systems based on an internal component model library containing several mechanical components including robot models. These models already contain the functional interaction of mechanical behaviour with actuators and sensors. If it is possible to compose the virtual manufacturing system from such library components - high-level modelling - it is relatively easy to set up and conduct $\mathrm{VC}$, where some additional effort arises when composing the plant model within the $3 \mathrm{D}$ editor, configuring $\mathrm{I} / \mathrm{O}$ connections and transferring controller programs.

\section{Low-level Modelling}

If there are no appropriate simulation models available in the library, the effort is far greater because it is necessary to build new models based on CAD data, which is not only a problem in CIROS $^{\circledR}$ but similarly for other simulation tools such as e.g. Delmia Automation ${ }^{\circledR}$. This low-level modelling comprises the whole functional chain, and is a non-trivial task requiring considerable modelling expertise (Park et al. 2006). Here it is necessary to carry out the geometrical, functional and electrical modelling to create a structured mechatronic component model.

\section{Geometrical Modelling}

The generation of a structured mechatronic model starts with the import of the geometry data from a CAD system. For this purpose CIROS $^{\circledR}$ provides import filters for e.g. STEP and IGES. Manual simplification of overly complex geometry data may become necessary:The import of standard CAD data often results in an unstructured geometrical model as shown in figure 1 (1), illustrating an example component for a transportation system.

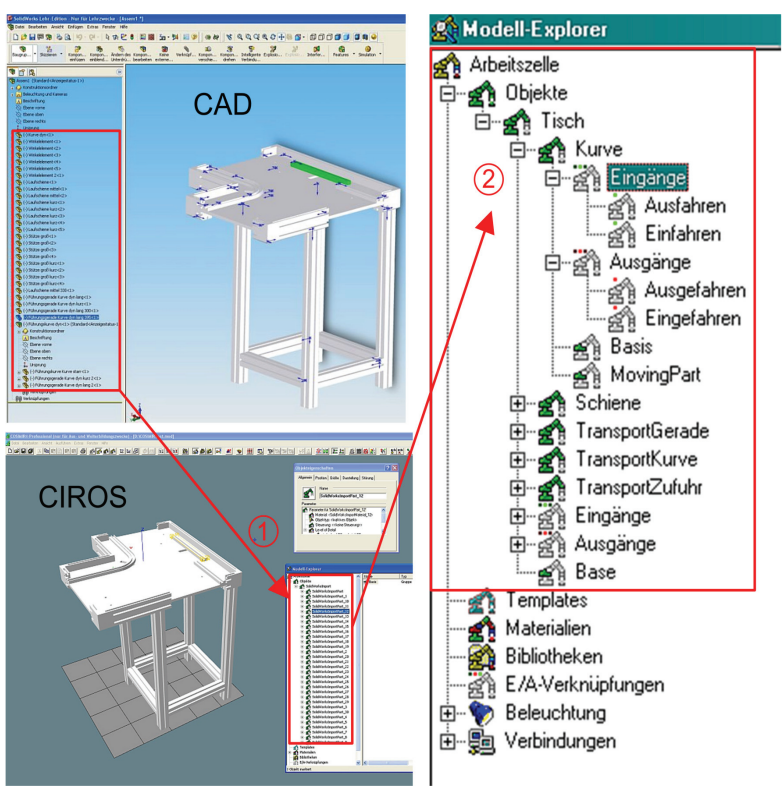

Figure 1: From CAD data to simulation object
In this case, manual hierarchical structuring of the CAD data into objects (like robots, sensors, tools or work pieces), sections (single static units e.g. joints of a robot) and components or hulls (describing the geometry e.g. cylinders, spheres or points), is the crucial step in creating the model adumbrated in figure 1- (2)). If the CAD data provided are not appropriately structured e.g. with regard to moving parts, the resulting geometrical model is not directly usable for the following functional modelling, nor would be a simulation based on such model. In the worst case a CAD redesign may become necessary to provide the necessary structures in the geometry data.

Having created appropriately structured geometrical models these must be provided with functions (functional modelling) and electrical inputs and outputs (electrical modelling).

\section{Functional Modelling}

In the functional modelling stage it is necessary to manually allocate actuator functions such as translation, rotation, gripping etc. and sensor functions to selected parts of the geometrical models, which results in the definition and parameterisation of integrated functional models such as cylinder, turntable, sensor, gripper and so on.

\section{Electrical Modelling}

For the final electrical modelling it is necessary to manually add electrical inputs/outputs to the functional models for later connection to inputs/outputs of control programs thus creating complete mechatronic models.

This low-level modelling procedure can only be done by "technically experienced persons with detailed knowledge of mechanical, electrical, pneumatic, and geometric data of single components" (Wischnewski and Freund 2004).

\section{NEW CONCEPTS FOR SIMPLIFIED VC OF MANUFACTURING SYSTEMS}

The Model ${ }^{\text {CAT }}$ project (Hoyer et al. 2008) at the UASA Hannover demonstrated for chemical processes, that in principle it is possible to automatically generate simulation models of chemical processes for $\mathrm{VC}$ based on the data stored in a CAE planning tool. This allows to rapidly conduct a $\mathrm{VC}$ after planning, engineering and programming have been completed, at the latest, because then all necessary data for assembly and real commissioning are available in the CAE database.

This current project investigates to what extent the Model $^{\mathrm{CAT}}$ concept is transferable to manufacturing systems. A CAE planning tool with object oriented database will be used to hold the planning data and additional data needed for simulation (mechatronic models, control programs). The combination of various data (mechanical data, electrical data, programs if 
applicable, and data needed for simulation), together in a CAE planning database tool, is a novel approach. The vision is the combination of a CAE planning tool with a simulation tool like CIROS $^{\circledR}$ which should ideally make it possible to assemble the mechatronic components already existing in the CAE planning tool and then to simulate the system with $\operatorname{CIROS}^{\circledR}$. Thus, the manual high-level modelling procedure in $\operatorname{CIROS}^{\circledR}$ could be, at least, partly omitted as the plant simulation model with I/O mapping would be built automatically from the CAE planning database.

In order to validate this concept which would provide simplified generation of virtual manufacturing systems for VC, an overarching tool called the "Prototypical Engineering Modelling and Simulation Environment (PEMS)" was designed (Figure 2). CIROS $^{\circledR}$ as the central simulation tool plays one key role in PEMS, the other key role the CAE planning tool $\mathrm{COMOS}^{\circledR}$ with object-oriented database (COMOS 2010). Additional off the shelf tools are used for programming PLCs, robots and HMIs.

Prototypical Engineering Modelling and Simulation (PEMS)

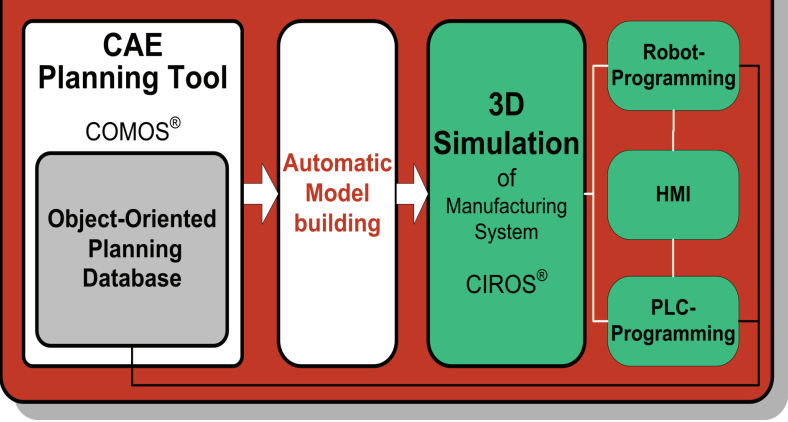

Figure 2: Prototypical Engineering, Modelling and Simulation Environment

Currently, CAE tools such as COMOS $^{\circledR}$ are mainly used for engineering planning and documentation purposes. The integration of data for the simulation of manufacturing systems has not been investigated hitherto.

The first task in developing PEMS is the investigation of how to automatically generate simulation models for CIROS $^{\circledR}$ from the CAE database, with the aid of an additional model building tool, in the case where the component models of the virtual manufacturing system already exist in a component library (high-level modelling).

Another task will be the investigation of systematic setup and extension of component model libraries, because typically projects in manufacturing systems may use new components for which simulation models do not exist in the component model library. Therefore the low-level modelling procedure needs systematisation where the formulation of requirements concerning function-oriented structuring of $\mathrm{CAD}$ data to geometrical objects by design engineers, is crucial.

In this project the set-up of exemplary simulation models in the component model library of the COMOS $^{\circledR}$ CAE database will be done manually in the first step. However, in future, importing such simulation models into the component database with minimum effort, is an important strategic point: one possible future strategy is the systematic collection of models from component and subsystem vendors (Figure 3), which may allow the provision of such models together with the hardware as predicted in (Schlögl 2007).

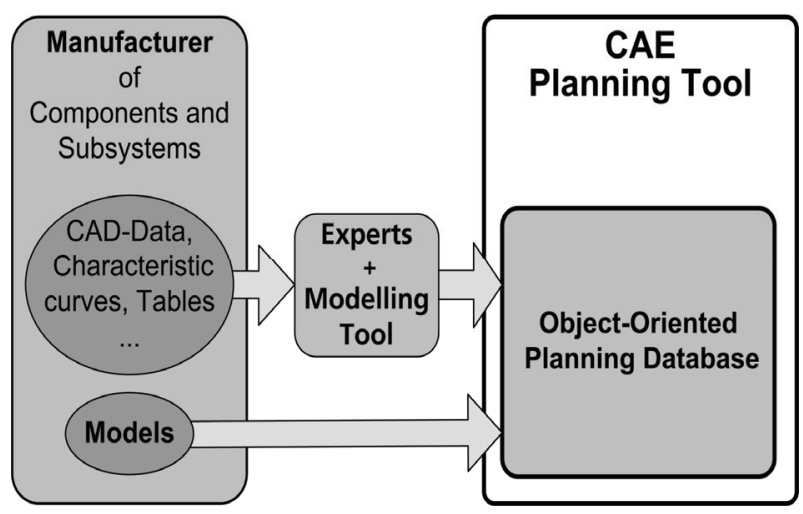

Figure 3: Future component model generation strategy

A promising new approach, supporting this strategy, is the development of AutomationML ${ }^{\circledR}$ (Drath 2010) by companies like Daimler, ABB, KUKA, Rockwell Automation and Siemens along with the Universities of Karlsruhe and Magdeburg and some smaller engineering companies. AutomationML ${ }^{\circledR}$ will provide an intermediate format for automation data exchange including component model data. AutomationML ${ }^{\circledR}$ uses CAEX as top level format for the description of the topology, COLLADA for geometry and kinematics and PLCopen XML for the overall behaviour (including electrical and control). The intention is the reduction of engineering efforts and improvement of quality by interconnecting heterogeneous tools, which may become especially valuable when setting up $\mathrm{VC}$ with different tools and exchange of model data using AutomationML $^{\circledR}$ (Drath et al. 2008a).

\section{Test Bed Validation of the Concept}

The test bed selected to investigate the "Prototypical Engineering Modelling and Simulation Environment (PEMS)" is a small pilot manufacturing cell, referred to as "Robot-based Flexible Assembly System" at the UASA Hannover. It consists of a Siemens S7 PLC controlled transportation system with autonomous trackbound transport cars, an associated elevator and two robot-based assembling units (SCARA robot and robotic palletiser) as shown in figure 4. The robotic palletiser contains a Berger-Lahr Motion controller/Soft PLC programmed with CoDeSys, the SCARA robot is programmed with a proprietary robot language. The 
transportation system includes an identification and data storage system which consists of data read/write stations on the tracks and mobile data carriers in the transport cars.

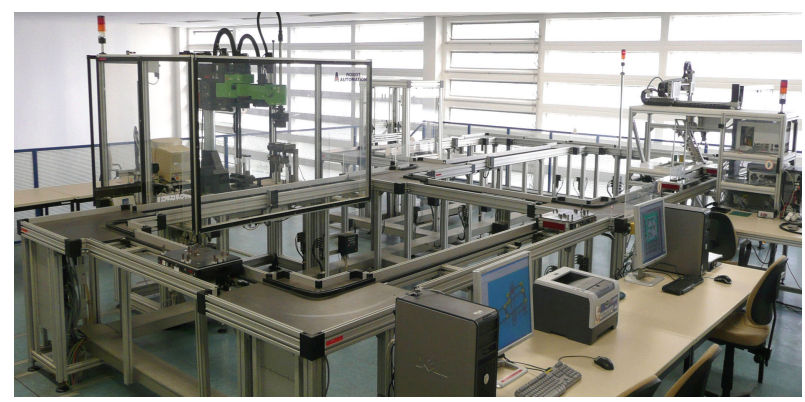

Figure 4: Robot-based Flexible Assembly System

The validation of the new PEMS approach for a simplified VC procedure will start with the low-level modelling of hardware components while following the defined modelling systematic, and storing component models of the pilot manufacturing cell in the CAE planning database of $\operatorname{COMOS}^{\circledR}$. After re-engineering of the pilot manufacturing cell in $\operatorname{COMOS}^{\circledR}$ the next validation step will be the automated (as far as possible) model building of the virtual manufacturing cell for simulation using CIROS $^{\circledR}$. The validation will end with the execution of a $\mathrm{VC}$, during which the system functions, including mechanical behaviour and control functions, will be tested by simulation. Purposely selected faults will be contrived in order to determine the efficiency of $\mathrm{VC}$.

\section{SUMMARY AND FUTURE PROSPECTS}

This project is expected to demonstrate how it could become possible for control system engineers and commissioning engineers to conduct a VC for manufacturing systems based on planning data, without requiring a high level of expertise in model building and simulation. This will necessitate that CAE and simulation tools provide the appropriate functionality, especially high-level simulation model building from the CAE planning database. In addition to the improved tool environment, the object-oriented database containing simulation models of manufacturing system components, will be the subject of detailed investigations and testing. From the authors point of view it is reasonable and essential to relocate the lowlevel modelling effort as far as possible to the component source, i.e. to the designers, manufacturers and suppliers of components or subsystems. The manufacturers should be encouraged to provide mechatronic simulation models of their components. To support this purpose procedural methods for simplified low-level modelling strategies are investigated in the context of this project. The resulting component or subsystem models should be tool-independent, because it is not reasonable for the manufacturers to create different models for different CAE planning tools and/or simulation tools. For this purpose it will be necessary to define a standardised structure and data format for mechatronic models in future. AutomationML ${ }^{\circledR}$ is an applicable format and has the potential to support such data formats. Customer request for component simulation models, not only CAD data (which are currently often hard to use for simulation) or electronic datasheets, would accelerate this process. Experts from universities, in cooperation with component manufacturers, should make the first move to build up exemplary simulation model libraries of components or subsystems, for use in CAE environments like the proposed PEMS.

The new approach presented here, with the pilot manufacturing cell acting as test bed for the prototype implementation, will show a solution roadmap to reduce the considerable efforts required for the modelling process to such a degree that also moderately resourced small and medium-sized enterprises may become able to employ VC to optimise their engineering processes.

\section{REFERENCES}

Auinger, F., Vorderwinkler, M. and Buchtela, G. 1999. "Interface driven domain-independent modeling architecture for 'soft-commissioning' and 'reality in the loop'", Proceedings of the 1999 Winter Simulation Conference, Phoenix, AZ, USA, 1, pp. 798-805.

Bani Younis, M. and Frey, G. 2003. "Formalization of existing PLC programs: A Survey", CESA 2003, Lille (France).

Comos Industry Solutions. 2010. COMOS, Available: http://www.comos.com [accessed 02. Feb. 2010]

Danielsson, F., Moore, P. and Eriksson, P. 2003. "Validation, off-line programming and optimisation of industrial control logic", Mechatronics, 13, 6, pp. 571-585.

Drath, R. (Ed.) 2010. "Datenaustausch in der Anlagenplanung mit AutomationML ", Springer Verlag, Berlin Heidelberg, pp. 326

Drath, R., Lüder, A., Peschke, J. and Hundt, L. 2008a. "AutomationML - the glue for seamless automation engineering", IEEE International Conference on Emerging Technologies and Factory Automation, ETFA 2008, Hamburg, pp. 616-623.

Drath, R., Weber, P. and Mauser, N. 2008b. "An evolutionary approach for the industrial introduction of virtual commissioning", IEEE International Conference on Emerging Technologies and Factory Automation, ETFA 2008, Hamburg, pp. 5-8.

Freund, E. and Rossmann, J. 1995. "Systems approach to robotics and automation", Proceedings of the 1995 IEEE International Conference on Robotics and Automation, Nagoya vol.1, pp. 3-14.

Freund, E., Rossmann, J., Uthoff, J. and Can Der Valk, U. 1994. "Towards realistic simulation of robotic workcells", Proceedings of the IEEE/RSJ/GI International Conference on Intelligent Robots and Systems '94. 'Advanced Robotic Systems and the Real World', IROS '94., Munich, 1, pp. $39-46$.

Hoyer, M., Schumann, R., Hoffmann, P. and Premier, G. C. 2008. "Virtuelle Inbetriebnahme mit Model $^{\mathrm{CAT}}$ - Vom Prototypen zum industriellen Einsatz / Virtual Start-Up with Model ${ }^{\mathrm{CAT}}$ - From Prototypical Realisation to Industrial Implementation", Automation 2008, BadenBaden, VDI-Berichte 2032, pp. 203-206. 
Kühn, W. 2006. "Digital Factory - Simulation Enhancing the Product and Production Engineering Process", Proceedings of the Winter Simulation Conference WSC 06., pp. 1899-1906.

Moore, P. R., Pu, J., Ng, H. C., Wong, C. B., Chong, S. K., Chen, X., Adolfsson, J., Olofsgard, P. and Lundgren, J. O. 2003. "Virtual engineering: an integrated approach to agile manufacturing machinery design and control", Mechatronics, 13, 10, pp. 1105-1121.

Park, C. M., Bajimaya, S. M., Park, S. C., Wang, G. N., Kwak, J. G., Han, K. H. and Chang, M. 2006. "Development of Virtual Simulator for Visual Validation of PLC Program", International Conference on Computational Intelligence for Modelling Control and Automation, and International Conference on Intelligent Agents, Web Technologies and Internet Commerce (CIMCA-IAWTIC'06).

Reinhart, G. and Wünsch, G. 2007. "Economic application of virtual commissioning to mechatronic production systems", Production Engineering, 1, 4, pp. 371-379.

RIF - Dortmunder Initiative zur rechnerintegrierten Fertigung (RIF) e. V. 2010. CIROS Engineering, Available: http://www.ciros-engineering.com/en.html [accessed 02 . Feb. 2010]

Rossmann, J., Stern, O. and Wischnewski, R. 2007. "Eine Systematik mit einem darauf abgestimmten Softwarewerkzeug zur durchgängigen Virtuellen Inbetriebnahme von Fertigungsanlagen von der Planung über die Simulation zum Betrieb", atp Automatisierungstechnische Praxis, 2007, 07, pp. 52-56.

Schlögl, W. 2007. "Einsatz der Digitalen Fabrik von der Anlagenplanung bis in den Laufenden Betrieb", GMAKongress 2007, Baden-Baden, VDI-Berichte 1980, pp. 717-725.

Thapa, D., Park, C. M., Dangol, S. and Wang, G.-N. 2006 "III-Phase Verification and Validation of IEC Standard Programmable Logic Controller", International Conference on Computational Intelligence for Modelling Control and Automation and International Conference on Intelligent Agents,Web Technologies and Internet Commerce (CIMCA-IAWTIC'06).

VDI-Gesellschaft Fördertechnik Materialfluss Logistik 2008. VDI-Richtlinie 4499 - Blatt 1: Digitale Fabrik Grundlagen

Westkämper, E., Bierschenk, S. and Kuhlmann, S. 2003. "Digitale Fabrik - nur was für die Großen?", wt Werkstattstechnik online, 93, 1/2, pp. 22-26.

Wischnewski, R. 2007. "Virtuelle Inbetriebnahme", $A \& D$ Kompendium 2007/2008, pp. 64-66.

Wischnewski, R. and Freund, E. 2004. "COSIMIR Transport: Modeling, simulation and emulation of modular carrier based transport systems", International Conference on Robotics \& Automation, New Orleans, LA, United States, 2004, pp. 5171-5176.

Zäh, M. F. and Wünsch, G. 2005. "Schnelle Inbetriebnahme von Produktionssystemen", wt Werkstattstechnik online, 95, 9, pp. 699-704

Zäh, M. F., Wünsch, G., Hensel, T. and Lindworsky, A. 2006. "Nutzen der virtuellen Inbetriebnahme: Ein experiment Use of virtual commissioning: An experiment", $Z W F$ Zeitschrift fuer Wirtschaftlichen Fabrikbetrieb, 101, 10, pp. 595-599.

\section{AUTHOR BIOGRAPHIES}

Peter Hoffmann was born in Hannover, Germany and went to the University of Applied Sciences and Arts
Hannover where he studied computer engineering and obtained his Dipl.-Ing. degree in 2000. He is now working as research staff member at the automation engineering lab at the same university, and he is currently a PhD student at the Faculty of Advanced Technology at the University of Glamorgan. His main research interest is in the field of control design for manufacturing systems and more specifically he is interested in verification and validation of PLC programs. His e-mail address is :

Peter.Hoffmann@fh-hannover.de

Reimar Schumann received the $\mathrm{PhD}$ degree in Automatic Control from the Technical University Darmstadt in 1982. During his industrial career he was responsible for the design and development of a third generation digital process control system. Since 1989 he is teaching process control at the University of Applied Sciences and Arts Hannover. His current research interest is focussed on process and production control and system design. His e-mail address is : Reimar.Schumannefh-hannover.de

Talal M. A. Maksoud is a Reader in the University of Glamorgan. He has over 30 years experience in research. He has published over 75 papers in Journals and international conferences. He has published several best papers in the field of advanced grinding technology. His main interests are in Grinding technology, heat transfer analyses, computational fluid dynamics, Aerodynamics, and Artificial Intelligence use in Manufacturing. Dr Maksoud has supervised over dozen PhD's as well as MPhil's. He has acted as external and internal examiner for several PhD's. He is a recognised referee for several peer reviewed academic Journals.

His e-mail address is : tmaksoudeglam.ac.uk

Giuliano C. Premier is a Reader in Low Carbon Systems Engineering and senior member of the Sustainable Environment Research Center (SERC). His research activities cover modelling, control, instrumentation, renewable energy systems, biological wastewater treatment. His Ph.D. concerned the modelling and control of anaerobic digestion (AD) processes and he has since been involved with research into anaerobic microbial processes. His research also includes industrial computer aided control system design (through a longstanding collaboration with the University of Applied Sciences, Hannover) and instrumentation for soil and groundwater bio-activity monitoring. He has and continues to contribute to collaborative projects with universities and industrial partners.

His e-mail address is : gcpremier@glam.ac.uk 